\section{Hi-Test: A Self-compatible Green Sprouting Broccoli Cultivar that Yields Seed with High Levels of Glucoraphanin}

\author{
Mark W. Farnham \\ U.S. Department of Agriculture, Agricultural Research Service, U.S. \\ Vegetable Laboratory, Charleston, SC 29414
}

Additional index words. Brassica oleracea-Italica Group, cole crops, inbred, self-compatible

A green sprouting broccoli (Brassica oleracea L. var. italica), designated 'Hi-Test', has been released by the Agricultural Research Service of the U.S. Department of Agriculture, and a Plant Variety Protection Certificate has been applied for it. 'Hi-Test' is a self-compatible, inbred cultivar that yields high-quality, uniform seed, containing high levels of the glucosinolate glucoraphanin (GR). This variety has very uniform growth characteristics, plant size, seed yield, and chemical makeup of the seed. 'HiTest' was derived from a cross of two genetically different inbred lines of green sprouting broccoli maintained in the U.S. Vegetable Laboratory (USVL) collection at Charleston, SC.

\section{Origin}

The parents used to make 'Hi-Test' include two green sprouting broccoli inbreds, one of which is a selection from the open-pollinated heirloom variety 'DiCicco', and the other a selection from an open-pollinated accession designated 'Cavolo Broccolo Ramoso' maintained in the USVL collection. Both parental inbreds were developed at Charleston and identified as self-compatible lines that produced seed with GR levels of 60 to 80 $\mu \mathrm{mol} \cdot \mathrm{g}^{-1}$ seed.

An $\mathrm{F}_{1}$ was made by crossing the parental inbreds in a greenhouse during Winter 200607 . The resulting $F_{1}$ seed was planted in the greenhouse in Fall 2007, and $F_{2}$ seed was generated over the winter. Approximately $400 \mathrm{~F}_{2}$ plants were grown to vegetable maturity in the field at Charleston during Fall 2008, and five robust plants were selected and moved to the greenhouse where they were grown in pots and allowed to self-pollinate during Winter 2009. Resulting $\mathrm{F}_{3}$ families were grown in the field during Fall 2009, and

Received for publication 18 Sept. 2019. Accepted for publication 15 Jan. 2020.

Published online 6 April 2020.

M.W.F. is a Research Geneticist.

M.W.F. is the corresponding author. E-mail: Mark. Farnham@ars.usda.gov.

This is an open access article distributed under the CC BY-NC-ND license (https://creativecommons.org/ licenses/by-nc-nd/4.0/). individual plants selected again, returned to a greenhouse, and allowed to self-pollinate over the winter. $\mathrm{F}_{4}$ seed was advanced for five different lines in the greenhouse for four additional generations to produce $\mathrm{F}_{8}$ seed by single seed descent. After testing verified self-compatible pollination in the absence of insect pollinators (Farnham and Harrison, 2003), good seed yield potential, and seed tions of $100 \mu \mathrm{mol} \cdot \mathrm{g}^{-1}$ dry seed or greater for one $\mathrm{F}_{8}$ line, it was ultimately designated 'HiTest'.

\section{Description}

'Hi-Test' plants have a classic blue-green color (e.g., relatively standard for broccoli) that matches the Munsell color with Hue 2.5 G, Value (Brightness) 5, and Chroma 2. This color is exhibited by foliage and mature heads and it is characteristic of many conventional broccoli cultivars (Fig. 1); however, it GR that was initially measured at concentra- is distinguishable from that of 'Hopkins', which has foliage and heads that exhibit the Munsell color with Hue 7.5 GY, Value 5, and Chroma 2.

Exact maturity of broccoli, based on when the vegetable head reaches a mature size (e.g., $10-12 \mathrm{~cm}$ diameter), will vary depending on the season and growing degree days (Farnham et al., 2004), but 'HiTest' will usually make mature heads 70 to $80 \mathrm{~d}$ after transplanting during a fall season in the Carolinas (Table 1). Planted at the same time, 'Castle Dome' will produce heads about $10 \mathrm{~d}$ earlier than 'Hi-Test', whereas 'Emerald Crown' is only $\approx 5 \mathrm{~d}$ earlier (Table 1). 'Hopkins' and 'Bay Meadows have similar and later maturity, producing heads $\approx 5$ or more d later than 'Hi-Test'.

'Hi-Test' is similar in height to 'Castle Dome' at head maturity. Mean heights to the top of the plant were $51.6 \pm 3.0 \mathrm{~cm}$ and $59.0 \pm$ $3.5 \mathrm{~cm}$ for field-grown 'Hi-Test' in 2017 and 2018 , respectively, and were $51.9 \pm 1.7 \mathrm{~cm}$ and $63.1 \pm 6.5 \mathrm{~cm}$, respectively, for 'Castle Dome' grown in the same trials (Table 1). 'Bay Meadows' was more than $10 \mathrm{~cm}$ taller than 'Hi-Test', and 'Hopkins' was less than 5 $\mathrm{cm}$ taller than 'Hi-Test' in the same trials (Table 1). 'Hi-Test' head weights at maturity were $159 \pm 26 \mathrm{~g}$ and $202 \pm 24 \mathrm{~g}$ in 2017 and 2018, respectively, whereas 'Castle Dome', 'Emerald Crown', and 'Bay Meadows' all yielded mature head weights greater than $200 \mathrm{~g}$ in all comparison trials. Mature head weights of 'Hopkins' are always less than those of 'Hi-Test', ranging from 100 to $175 \mathrm{~g}$, depending on the growing season.

Head quality characteristics of 'Hi-Test' are lower than currently demanded for freshmarket broccolis (Table 1). 'Hi-Test' heads are also not as dense or firm as standard freshmarket heads (Table 1). In addition, bead or

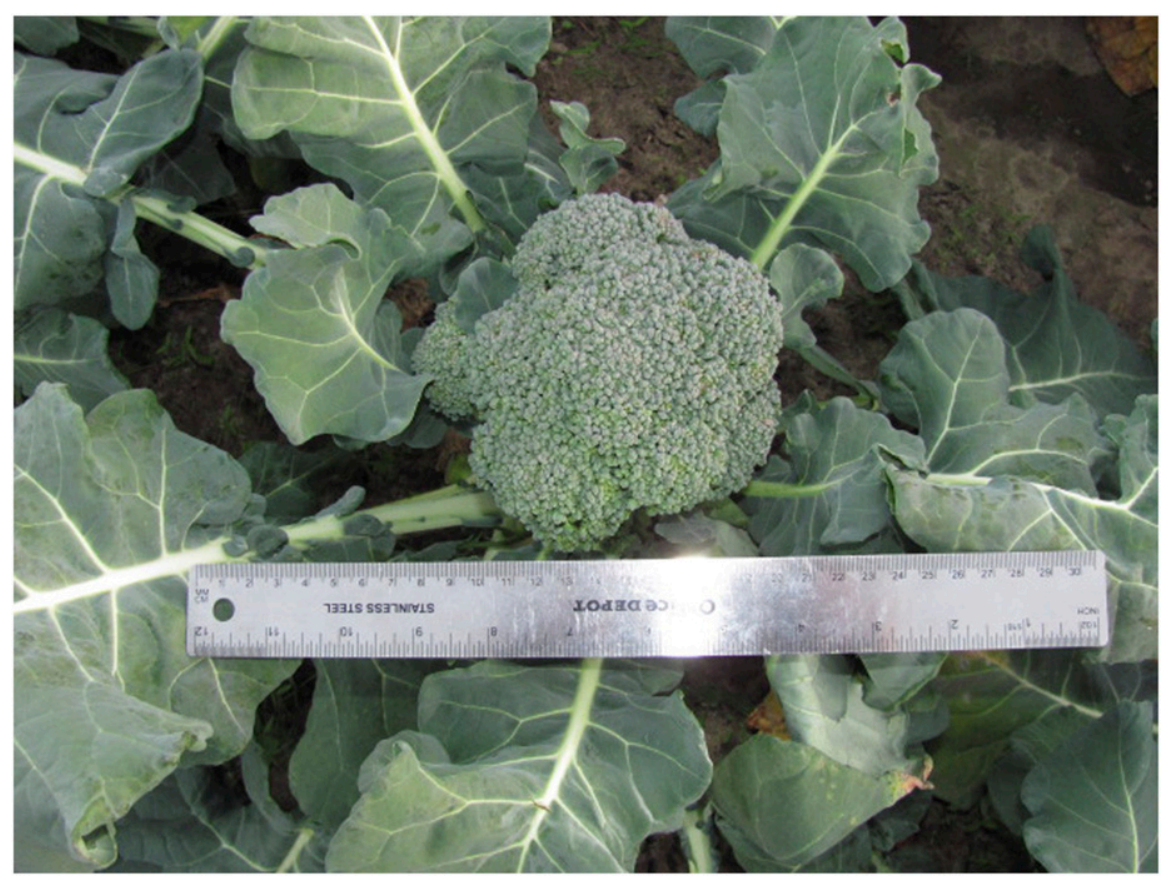

Fig. 1. A head of 'Hi-Test' broccoli at a mature head stage in the field in Charleston in Fall 2017. 
Table 1. Mean attributes of 'Hi-Test' broccoli, including days to harvest, head shape, head mass, stem diameter, plant height, head height, and crown depth, compared to the other check cultivars (Hopkins, Castle Dome, Emerald Crown, and Bay Meadows) measured in the field in 2017 and 2018 . Numbers in parentheses represent standard deviations of the respective means computed from all plants measured for a cultivar in a given year.

\begin{tabular}{|c|c|c|c|c|c|c|c|c|}
\hline & $\begin{array}{l}\text { Maturity } \\
\text { (d) }\end{array}$ & $\begin{array}{l}\text { Head shape }^{y} \\
\text { (rating) }\end{array}$ & $\begin{array}{c}\text { Head mass } \\
(\mathrm{g})\end{array}$ & $\begin{array}{l}\text { Stem diam }{ }^{\mathrm{w}} \\
(\mathrm{mm})\end{array}$ & $\begin{array}{l}\text { Plant ht }{ }^{\mathrm{v}} \\
\quad(\mathrm{cm})\end{array}$ & $\begin{array}{l}\text { Head ht } \\
\quad(\mathrm{cm})\end{array}$ & $\begin{array}{l}\text { Dome depth } \\
(\mathrm{cm})\end{array}$ & $\begin{array}{c}\text { Overall quality } \\
\text { (rating) }\end{array}$ \\
\hline \multicolumn{9}{|c|}{$2017^{r}$} \\
\hline Hi-Test & 75 & $2.5(0.3)$ & $159(26)$ & $33(4)$ & $51.6(3.0)$ & $44.3(4.7)$ & $5.1(0.5)$ & $2.3(0.3)$ \\
\hline Hopkins & 86 & $2.3(0.4)$ & $117(12)$ & $23(2)$ & $53.7(8.7)$ & $39.6(3.0)$ & $4.9(0.2)$ & $1.7(0.3)$ \\
\hline Castle Dome & 68 & $3.4(0.3)$ & $220(15)$ & $37(3)$ & $51.9(1.7)$ & $31.4(4.0)$ & $6.5(0.5)$ & $3.2(0.3)$ \\
\hline Emerald Crown & 70 & $4.1(0.3)$ & $245(22)$ & $38(2)$ & $56.0(1.2)$ & $30.1(3.2)$ & $6.8(0.3)$ & $3.9(0.2)$ \\
\hline Bay Meadows & 82 & $3.3(0.3)$ & 206 (14) & $37(2)$ & $64.7(5.8)$ & $37.9(1.2)$ & $5.9(0.2)$ & $3.9(0.2)$ \\
\hline $\operatorname{LSD}_{0.05}{ }^{\mathrm{r}}$ & 7 & 0.4 & 30 & 4 & 7.5 & 6.0 & 0.6 & 0.4 \\
\hline \multicolumn{9}{|c|}{$2018^{r}$} \\
\hline Hi-Test & 71 & $2.3(0.1)$ & $202(24)$ & $36(4)$ & $59.0(3.5)$ & $38.8(3.6)$ & $3.9(0.7)$ & $2.6(0.2)$ \\
\hline Hopkins & 74 & $2.6(0.4)$ & $175(18)$ & $27(5)$ & $63.3(4.1)$ & $40.3(4.1)$ & $4.7(0.7)$ & $2.1(0.3)$ \\
\hline Castle Dome & 60 & $3.1(0.2)$ & $335(41)$ & $44(2)$ & $63.1(6.5)$ & $30.4(1.5)$ & $5.9(0.7)$ & $2.9(0.4)$ \\
\hline Emerald Crown & 65 & $3.9(0.3)$ & $299(56)$ & $37(5)$ & $69.5(5.9)$ & $32.8(1.8)$ & $6.8(0.5)$ & $4.1(0.3)$ \\
\hline Bay Meadows & 80 & $3.9(0.3)$ & $270(20)$ & $33(3)$ & $74.8(2.3)$ & $43.5(1.8)$ & $6.5(0.4)$ & $4.3(0.3)$ \\
\hline $\mathrm{LSD}_{0.05}$ & 7 & 0.3 & 59 & 6 & 8.5 & 4.4 & 1.0 & 0.2 \\
\hline
\end{tabular}

${ }^{\mathrm{z}}$ Maturity is measured as days from transplant to harvest.

${ }^{\mathrm{y}}$ Head shape is a rating from 1 to 5 as previously described by Stansell et al. (2017). 1 is flat to concave, 3 is slightly domed, and 5 is a high dome.

${ }^{\mathrm{x}}$ Head mass is that taken from a head cut at head diameter of about $10 \mathrm{~cm}$ with length of head cut to $16 \mathrm{~cm}$.

${ }^{\mathrm{w}}$ Stem diameter is taken at the base of the heads sampled for head mass.

vPlant height is a measure of the height from the soil level to the top of the tallest part of the plant.

${ }^{\mathrm{u}} \mathrm{Head}$ height is a measure of the height from soil level to the top of the head.

${ }^{\mathrm{t}}$ Dome depth is measured from the base of the crown to the top of the crown of heads sampled for head mass.

${ }^{\mathrm{s}}$ Overall quality of each sampled head was rated on a 1 to 5 scale as described by Stansell et al. $(2017) .1=$ very poor quality, $3=$ marketable quality, $5=$ excellent quality.

${ }^{\mathrm{r}}$ In both 2017 and 2018, cultivars were evaluated in a field experiment having a randomized complete block design with three replications. The experimental unit was a plot containing 20 plants of a given cultivar spaced 6 inches apart and set on raised beds on 40 -inch centers. Seedlings were transplanted to the field 21 Sept. 2017 and 17 Sept. 2018.

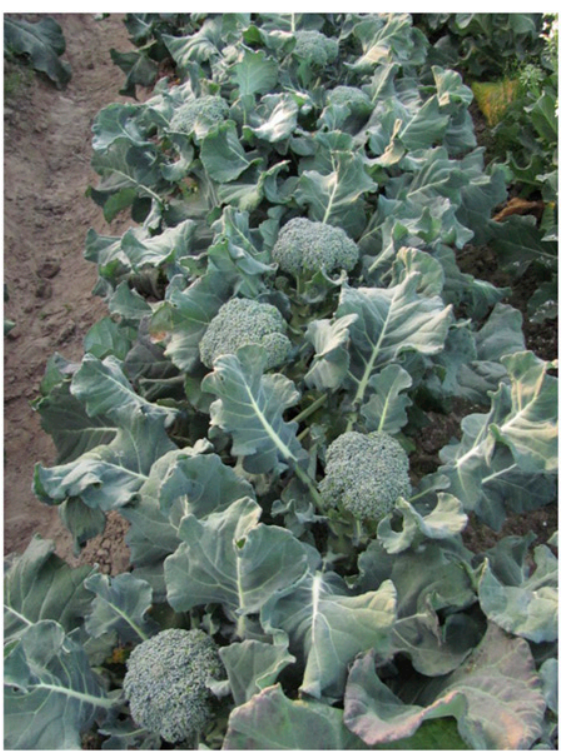

Fig. 2. A plot of 'Hi-Test' broccoli with heads at a mature stage in the field in Charleston in Fall 2017.

bud size is not as small, and head shape is not as domed as it is with heads produced by standard, fresh-market broccoli hybrids like 'Emerald Crown' (Table 1).

Nearly all modern commercial cultivars of broccoli developed for vegetable production are $\mathrm{F}_{1}$ hybrids, and all plants of a given hybrid are genetically homogeneous, but highly heterozygous. On the contrary, 'Hi-Test' is a highly homogeneous cultivar produced by selfpollination, and plants of this cultivar are highly homozygous and inbred (Fig. 2). These attributes make 'Hi-Test' similar to 'Hopkins' (a previous release of the U.S. Vegetable Laboratory program), which is also a homo- zygous inbred that readily produces selfed seed. 'Hopkins' was developed from the highly heterogeneous, open-pollinated heirloom broccoli known as 'Italian Green Sprouting'. Thus, it has a very different pedigree than 'Hi-Test'.

Unlike most broccoli cultivars, like 'Castle Dome' and 'Bay Meadows' grown almost exclusively for fresh-market broccoli heads, 'Hi-Test' was developed as a producer of broccoli seed containing high levels of GR. To accomplish seed production with 'Hi-
Test', which is also true for 'Hopkins', this variety must be grown 60 to $80 \mathrm{~d}$ in the greenhouse or field past the stage when mature heads are produced, so that pollination, fertilization, pod development, seed set, and seed maturation can all be completed (Fig. 3) (USDA, 2006). The flowers of 'Hi-Test' are the standard bright yellow color of broccoli flowers that would be similar for 'Hopkins', 'Castle Dome', and 'Emerald Crown', as well as for nearly all broccoli. Seed color of 'HiTest' is dark brown to nearly black, making it



Fig. 3. Two plants on the left are individuals of 'Hopkins' approaching the pod and seed maturation stage, and two plants on the right are individuals of 'Hi-Test' approaching the same stage. 
difficult to distinguish visibly from 'Hopkins' seed, which has a similar color. Although 'HiTest' and 'Hopkins' were developed as broccoli seed producers, most modern $\mathrm{F}_{1}$ hybrids of broccoli like 'Castle Dome', 'Emerald Crown', and 'Bay Meadows' are effectively sterile and will not produce seed in the absence of foreign pollen and insect pollinators because they are made using cytoplasmic male sterility.

GR content of broccoli seed and other parts of the plant are largely affected by genotype and known to be highly heritable; however, the environment also has some influence on the relative amount of GR in seed, and exact amounts will vary from year to year (Farnham et al., 2004, 2005). GR contents of seed samples produced over 3 years for this germplasm characterization study were measured by an analytical company (Exact Scientific Services, Inc., Ferndale, WA) using a direct-measure high-performance liquid chromatography method that uses a hydrophilic interaction chromatography column (Wade et al., 2007). GR levels measured in 'Hi-Test' seed produced in outdoor cages or small field grow-outs conducted in the Yuma Valley of Arizona or the Imperial Valley of California in 2016, 2017, and 2018 were 120, 146 , and $142 \mu \mathrm{mol} \cdot \mathrm{g}^{-1}$ seed, respectively, which were higher levels than originally detected (e.g., $\approx 100 \mu \mathrm{mol} \cdot \mathrm{g}^{-1}$ seed) in seed lots produced in a greenhouse. Similar lots of 'Hopkins' produced in the same environments in the same years were 93, 100, and 107 $\mu \mathrm{mol} \cdot \mathrm{g}^{-1}$ seed. The higher relative concentrations of GR in Hi-Test seed makes it a desirable cultivar for private or public interests growing broccoli seed for sprouting or as a relatively cheap source of GR.

The U.S. Department of AgricultureAgricultural Research Service has applied for Plant Variety Protection for 'Hi-Test', and it will be available for use under a licensing agreement with the agency. The genetic materials of this release will be deposited in the National Plant Germplasm System, where they will ultimately be available for research purposes only, as well as for the development and commercialization of new cultivars.

\section{Literature Cited}

Farnham, M.W. and H.F. Harrison. 2003. Using self-compatible inbreds of broccoli as seed producers. HortScience 38:85-87.

Farnham, M.W., K.K. Stephenson, and J.W. Fahey. 2005. Glucoraphanin level in broccoli seed is largely determined by genotype. HortScience 40:50-53.

Farnham, M.W., P.E. Wilson, K.K. Stephenson, and J.W. Fahey. 2004. Genetic and environmental effects on glucosinolate content and chemoprotective potential of broccoli. Plant Breed. 123:60-65.

Stansell, Z., T. Bjorkman, S. Branham, D. Couillard, and M.W. Farnham. 2017. Use of a quality trait index to increase the reliability of phenotypic evaluations in broccoli. HortScience 52:1490 1495.

U.S. Department of Agriculture. 2006. Plant Variety Protection Certificate for 'Hopkins' broccoli. PVP No. 200700022. U.S. Department of Agriculture, Washington, DC.

Wade, K.L., I.J. Garrard, and J.W. Fahey. 2007. Improved hydrophilic interaction chromatography method for the identification and quantification of glucosinolates. J. Chromatography 1154:469-472. 